\title{
IL-17 receptor and its functional significance in psoriatic arthritis
}

\author{
Siba P. Raychaudhuri · Smriti K. Raychaudhuri • \\ Mark C. Genovese
}

Received: 18 April 2011/Accepted: 13 August 2011/Published online: 6 September 2011

(C) Springer Science+Business Media, LLC. 2011

\begin{abstract}
To delineate the functional significance of IL17 Receptor (IL-17RA) and characterize the IL-17 producing $T$ cell $\left(\mathrm{T}_{\mathrm{h}} 17\right)$ subpopulation in psoriatic arthritis (PsA). Mononuclear cells from blood and synovial fluid (SF) were obtained from PsA $(n=20)$, rheumatoid arthritis (RA, $n=20$ ) and osteoarthritis (OA, $n=20$ ) patients. Synoviocytes (FLS) were isolated from the synovium of RA $(n=5)$, PsA $(n=5)$ and OA $(n=5)$ patients. IL-17RA expression in FLS was identified by western blotting (WB) and flowcytometry. T lymphocytes derived from the SF of these patients were studied to identify and phenotype the $T_{h} 17$ cells. The functional significance of IL-17RA was determined by evaluating its regulatory role on the production of proinflammatory cytokines and endopeptidase. IL-17RA expression was found to be significantly higher in FLS of RA $(15.7 \% \pm 4.9)$ and PsA $(4.5 \% \pm 0.9)$ in comparison to OA $(1.14 \% \pm 0.9)$. Western blot analyses showed that the relative intensity (RI) of IL-17RA protein was higher in RA and PsA compared to OA (Fisher exact, $P<0.01$ ). A significant enrichment of IL-17-producing CD4+ T cells $(7.9 \% \pm 2.8)$ was observed in the SF of PsA patients compared to that of OA patients $(P<.001)$. Compared to OA-FLS, recombinant IL-17 induced higher levels of IL-6, IL-8, and MMP-3 production in PsA-FLS. Blockage of
\end{abstract}

S. P. Raychaudhuri $(\bowtie) \cdot$ S. K. Raychaudhuri Division of Rheumatology, Allergy \& Clinical Immunology, University of California Davis School of Medicine \& VA Medical Center Sacramento, 1911 Geneva Place, Davis, CA 95618, USA

e-mail: sraychaudhuri@ucdavis.edu

M. C. Genovese

Stanford University School of Medicine,

Immunology \& Rheumatology, Stanford, CA, USA
IL-17RA with an anti-IL-17RA antibody inhibited the production of IL-6, IL-8, and MMP-3. This is the first report to demonstrate the functional significance of IL17RA in PsA. Results of this study support the hypothesis that IL-17RA blocking antibodies have the potential to be a therapeutic option for psoriatic arthritis.

Keywords $T_{h} 17$ cells $\cdot$ IL-17/IL-17R $\cdot$ Psoriatic arthritis . Psoriasis $\cdot$ Synovial tissue $\cdot$ Synoviocytes/FLS
Abbreviations
IL-17 Interleukin 17
IL-17R IL-17 receptor
$\mathrm{T}_{\mathrm{h}} 17 \quad$ IL-17 producing $\mathrm{T}$ helper cells
IFN- $\gamma$ Interferon- $\gamma$
FLS Fibroblast like synovial cells
MMP-3 Matrix metalloproteinase-3
OA Osteoarthritis
PBMC Peripheral blood mononuclear cells
PsA Psoriatic arthritis
ROR $\gamma \mathrm{t} \quad$ Retinoic acid-related orphan receptor $\gamma \mathrm{t}$
SFMC Synovial fluid derived mononuclear cells
TGF $\beta \quad$ Transforming growth factor beta

\section{Introduction}

T-helper $17\left(\mathrm{~T}_{\mathrm{h}} 17\right)$ cells are a unique effector CD4+ T-cell subset characterized by their production of interleukin (IL)-17[1-4]. The binding of IL-17 to an IL-17 receptor expressed on epithelial, endothelial, or fibroblastic stromal cells induces significant events in many tissues. Through the ubiquitously expressed IL-17 receptor, IL-17 induces 
the secretion of proinflammatory cytokines $[5,6]$, recruits neutrophils/monocytes and triggers an immune mediated inflammatory reaction [7, 8]. IL-17 also stimulates osteoclast formation and bone resorption [9]. Aberrant $T_{h} 17$ cell responses have been linked to various murine autoimmune diseases, including collagen-induced arthritis, autoimmune encephalomyelitis, and primary biliary cirrhosis [10-12]. Recent studies also indicate that $\mathrm{T}_{\mathrm{h}} 17$ cells have a critical role in the pathogenesis of several human autoimmune diseases, such as rheumatoid arthritis, juvenile idiopathic arthritis, and psoriasis $[4,7,10,13,14]$.

Psoriasis is a chronic inflammatory disease of the skin. In addition to the cutaneous system, it often involves the musculoskeletal system and occasionally the gastrointestinal tract and eye. Therefore, it is often referred to as psoriatic disease, to encompass the varied involvement of diseased tissues and organs [15]. The role of $T_{h} 17$ in the pathogenesis of psoriasis is currently under investigation. IL-17A is elevated in psoriatic lesions and induces IL-6, IL-8, ICAM-I, and MHC II expression in keratinocytes [14, 16-18]; these biological features are characteristic of keratinocytes in lesional psoriasis. Very limited information is available on the role of IL-17 in psoriatic arthritis and there are no studies available about the distribution and functional significance of IL-17 R in psoriatic arthritis (PsA).

In this study, in order to determine the role of IL-17R in the pathogenesis of PsA and to explore IL-17R as a target therapeutic molecule for PsA following studies were performed: (i) IL-17RA expression was analyzed in synoviocytes (FLS) obtained from synovial tissues of patients with PsA and compared it with FLS from rheumatoid arthritis (RA) and osteoarthritis (OA) patients, (ii) $\mathrm{T}_{\mathrm{h}} 17$ cells were identified in synovial fluid from PsA patients and their phenotypes and functional significance were determined, (iii) the functional significance of IL-17R was investigated in FLS derived from PsA, and (iv) the regulatory role of IL17/IL-17RA system was further substantiated by evaluating whether a monoclonal antibody against IL-17RA (antihuman IL-17RA mAb, M202, Amgen, Thousand Oaks, CA [19]) inhibits IL-17-induced proinflammatory cytokine and metalloproteinase production.

\section{Materials and methods}

\section{Study population}

This study was approved by the Institutional Review Board of Stanford University and VAMC Sacramento. Specimens were collected from patients with active PsA, OA and RA, and healthy controls. OA and RA patients were recruited according to the clinical, laboratory, and radiographic classification criteria of the American College of
Rheumatology. Psoriatic arthritis patients had either oligoarthritis or symmetric polyarthritis as described by Moll and Wright [20]. All PsA patients fulfilled the CASPAR classification criteria for PsA. Patients had a complete physical examination, evaluation of severity of psoriasis and arthritis, appropriate blood tests and radiological studies. Synovial fluid (SF) and synovial tissues were collected from PsA, RA and OA patients with active arthritis of one or both knees. The inclusion criteria for RA and PsA utilized by this study were designed to limit participants to only those with the active disease. Active RA and PsA were defined by the presence of at least three swollen and three tender joints. In addition, for PsA the presence of plaque psoriasis with a qualifying lesion at least $2 \mathrm{~cm}$ in diameter was required. Body surface area (BSA) affected by psoriatic skin involvement was measured. Patients were evaluated for the swollen joint count, the tender joint count, patient's assessment of pain, ESR and CRP. We tried to enroll patients who have not taken DMARDs (methotrexate, leflunomide, cyclosporine, hydroxychloroquine, sulfasalazine, azathioprime) and biologic agents within last 3 months. Types of specimens, number of subjects, disease type and use of DMARDs for specific experiments are described in appropriate sections. Various assays were done on patient samples, as described under specific subheadings in the following sections.

Peripheral blood mononuclear cells (PBMC) and synovial fluid mononuclear cells (SFMC) were obtained from PsA $(n=20)$, RA $(n=20)$, and OA $(n=20)$ patients. Paired samples of PBMC and SFMC were obtained. All arthritis patients had active disease; they required therapeutic joint aspiration and/or intra-articular injection of steroids. $4 \mathrm{~mm}$ size punch biopsies were collected from psoriasis plaques $(n=25)$ and non-lesional psoriatic skin $(n=15)$. Biopsies of normal skin were used as controls $(n=15)$ from our tissue bank. Synovial tissues were studied from PsA $(n=5)$, RA $(n=5)$, OA $(n=5)$ and normal subjects with meniscal tear $(n=5)$. These subjects required an arthroscopic procedure or joint replacement.

Identification of IL-17 receptor and its functional significance

\section{Isolation of FLS from synovial tissue}

Synoviocytes/Fibroblast like synovial cells (FLS) were isolated from synovial tissue biopsies of healthy subjects with meniscal tears $(n=4)$, RA $(n=5)$, PsA $(n=5)$, and OA $(n=5)$. Synoviocyte cell suspensions were prepared from synovial tissues as described by Valencia et al. [21] and FLS were isolated in accordance with our standardized protocols [21-23]. After the third passage, cells appeared fibroblast-like and were negative with anti-CD68 
monoclonal antibody, suggesting they were composed mainly of FLS. Cells were maintained at $37^{\circ} \mathrm{C}$ in a humidified atmosphere of $95 \%$ air and $5 \% \mathrm{CO}_{2}$ and cultured in complete medium (DMEM with sodium pyruvate, penicillin, streptomycin, $10 \%$ fetal bovine serum). All FLS were positive for the fibroblast-specific markers ASO2 and CD55. No expression of the macrophage-specific marker CD68, or pan endothelial cell adhesion molecule (PECAM) CD31 could be detected in FLS cultures, thus excluding possible contamination from synovial fibroblasts by synovial macrophages and endothelial cells. All experiments were performed with cells between the third and fifth passages.

\section{IL-17RA expression on FLS by flowcytometry}

Adherent FLS were detached by accutase (PAA, Linz, Austria), washed with PBS and incubated with the mouse anti-human IL-17RA monoclonal antibody, M202 (20 ng/ $\mathrm{ml}$, Amgen USA), at $4^{\circ} \mathrm{C}$ for $20 \mathrm{~min}$. Cells were then washed with phosphate buffered saline (PBS) containing $2 \%$ fetal bovine serum and were incubated with goat antimouse IgG-FITC (BD-Pharmingen, San Diego, CA) for $20 \mathrm{~min}$ at $4{ }^{\circ} \mathrm{C}$. The cells were washed and fixed with $0.5 \%$ paraformaldehyde for FACS analysis. At least 100,000 cells were collected in FACSAria (BD Biosciences, San Jose, CA). Data were analyzed using FlowJo software (Treestar, Ashland, OR).

\section{Western blot analysis of IL-17RA}

FLS were washed twice with ice cold PBS. Cells were harvested by scraping into ice-cold RIPA buffer (PBS, $1 \%$ Nonidet P-40, $0.5 \%$ sodium deoxycholate). Inhibitors were added in the following concentrations: $1 \mathrm{mM} \mathrm{PMSF}, 1 \mathrm{mg} /$ $\mathrm{ml}$ aprotinin, $1 \mathrm{mg} / \mathrm{ml}$ leupeptin, $1 \mathrm{mg} / \mathrm{ml}$ pepstatin, $1 \mathrm{mM}$ Na3VO4 and $1 \mathrm{mM} \mathrm{NaF}$ (Sigma). The cell lysate was incubated at $4^{\circ} \mathrm{C}$ for $60 \mathrm{~min}$ and centrifuged at $14000 \mathrm{rpm}$ for $20 \mathrm{~min}$ at $4^{\circ} \mathrm{C}$; the supernatant was then collected. Protein concentration in the supernatant was quantified using the BCA Protein Assay Reagent Kit (Thermo-Fisher scientific, USA) and $30 \mu \mathrm{g}$ of cell lysate protein was used for western blot analysis. Proteins were electroblotted from NuPAGE gels (NOVEX, Frankfurt-Hoechst, Germany) onto a Hybond ECL membrane (Amersham, Freiburg, Germany). The membrane was blocked with $1 \%$ BSA in TBST for $1 \mathrm{~h}$ at room temperature. Blots were incubated with the primary antibody IL-17R mAb (Amgen, USA) at 1:250 dilution; $\alpha$-tubulin, (Cell signaling Technologies), 1:250 dilution in TBST with $1 \%$ BSA at room temperature for $2 \mathrm{~h}$. Blots were washed three times and then incubated for $1 \mathrm{~h}$ with 1:20000 dilution of goat anti-mouse IgG secondary antibody coupled with horseradish peroxidase
(Dianova, Hamburg, Germany). Immunodetection was accomplished using the ECL western blotting detection reagents (Thermo-Fisher Scientific, USA) for chemiluminescent detection. Immunoreactivity was quantified by scanning densitometry using Image $\mathrm{J}$ software $(\mathrm{NIH}$, Bethesda, MD, USA).

Inhibitory effect of IL-17RA mAb, M202, on IL-6, IL-8, and MMP3 production by IL-17-stimulated FLS

Third passage FLS (10000 cells/well) were cultured in DMEM complete medium with or without recombinant IL17 (10 ng/ml, ebiosciences), and/or IL-17RA monoclonal antibody $(20 \mathrm{ng} / \mathrm{ml}$, anti-human IL-17RA mAb, M202, Amgen, ) or TNF- $\alpha(10 \mathrm{ng} / \mathrm{ml})$ (eBiosciences, San Diego, CA) in 96-well plates for 5 days at $37^{\circ} \mathrm{C}$ in a humidified incubator with $5 \% \mathrm{CO}_{2}$. Then the supernatants were collected and stored at $-20^{\circ} \mathrm{C}$ for ELISA assay to determine the levels of IL-6, IL-8, and MMP3. ELISA kits were obtained from RayBiotech Inc., Norcross, GA. The minimum detection limit was $0.3 \mathrm{ng} / \mathrm{ml}$ for MMP3, $1 \mathrm{pg} / \mathrm{ml}$ for IL-8 and $6 \mathrm{pg} / \mathrm{ml}$ for IL-6.

Quantitative immunoassay of IL-17A (ELISA) in synovial fluid of psoriatic arthritis, rheumatoid arthritis, and osteoarthritis patients

Synovial fluid was collected from the knee joints of patients with PsA $(n=20)$, RA $(n=20)$, and OA $(n=20)$. All patients had active arthritis. The patients were on NSAID or Tylenol; no patient was taking corticosteroid or biologics. Seven patients with RA were taking hydroxychloroquine; five patients with PsA and six patients with RA were on methotrexate $(<10 \mathrm{mg} / \mathrm{wk})$. The synovial fluid was immediately centrifuged at $400 \times g$ for $20 \mathrm{~min}$ at $4^{\circ} \mathrm{C}$ to remove cells and debris. Supernatant were carefully removed and stored at $-20^{\circ} \mathrm{C}$. IL-17A concentration was measured by ELISA using RayBio ${ }^{\circledR}$ Human IL-17 ELISA Kit Protocol, RayBiotech, Norcross GA. For comparison, paired serum samples of the patients as well as serum from ten healthy subjects were used as controls. Sensitivity for IL-17 detection by this kit is $10 \mathrm{pg} / \mathrm{ml}$.

\section{Identification and phenotypic characterization} of the $T_{h} 17$ cells in psoriatic arthritis

Blood and synovial fluid from PsA $(n=12)$, RA $(n=8)$, and OA $(n=12)$ patients were studied. SFMC and PBMC were isolated by Ficoll-hypaque gradient centrifugation. Two million cells per well were activated by culturing for $72 \mathrm{~h}$ in a CD3/CD28 (5 $\mu \mathrm{g} / \mathrm{ml}$ each) coated 24-well plate. SFMC from four PsA subjects were also stimulated for $24 \mathrm{~h}$ with $1 \mu \mathrm{g} / \mathrm{ml}$ of phorbol myristate acetate 
(Sigma-Aldrich) and $0.25 \mu \mathrm{g} / \mathrm{ml}$ of ionomycin (SigmaAldrich). Monensin was added $6 \mathrm{~h}$ prior to harvesting the cells to block the secretion of intracellular cytokines from the cells. Then cells were washed and stained with LiveDead $^{\mathrm{TM}}$ marker (Molecular Probe Inc., Carlsbad, CA), surface markers of T cells (anti-CD3, CD4, CD8, CD11a, CD45RA antibodies) and intracellular cytokines (IL-17A, IFN- $\gamma$, and IL-4 antibodies) as per our standardized protocol. In brief, to study $\mathrm{T}$ cell surface markers, cells were incubated with respective fluorochrome conjugated antibodies (BD-Pharmingen, San Diego, CA) for $30 \mathrm{~min}$, washed twice and resuspended in PBS containing 2\% FBS. Next, the cell suspensions were treated with $250 \mu \mathrm{l}$ of cytofix/cytoperm reagent (BD-Pharmingen, San Diego, CA); cells were then washed with lysis buffer and resuspended in lysis buffer containing 2\% FBS and kept in ice. Subsequently, for intracellular staining, fluorochrome conjugated IL-17A, IFN- $\gamma$, and IL-4 antibodies (eBiosciences, San Diego, CA) were added to lysis buffer and incubated in ice for $30 \mathrm{~min}$. Finally, cells were washed twice and resuspended in PBS for FACS analyses. The controls used were unstained cells and cells stained with irrelevant primary mouse or rabbit antibodies. Unstained cells were used to determine autofluoresence. Cells were analyzed in FACSAria (Becton-Dickinson, San Jose, CA). At least 500,000 events were collected in DiVa electronic system. Data were analyzed using FlowJo software (Treestar Inc., Ashland, Oregon).

\section{Immunohistochemical staining}

Cryosections of $6 \mu \mathrm{m}$ thickness were prepared from synovial tissues and skin tissues on Superfrost Plus slides (VWR Scientific Products, West Chester, PA, USA). Sections were air-dried and fixed in cold acetone for $5 \mathrm{~min}$. Serial sections were stained for CD3 and IL-17A. Sections were washed in PBS $0.1 \%$ solution, then incubated for $20 \mathrm{~h}$ at $4{ }^{\circ} \mathrm{C}$ with monoclonal antibodies for IL-17A (eBiosciences) and CD3 (Boehringer Mannheim, Indianapolis, IN). Tissues were washed again with PBS and immunoperoxidase staining was performed as per our standardized protocol [24, 25]. The controls were sections stained by the same protocol except the primary antibody and sections stained with isotype antibody. In each section, the entire tissue was scanned for the presence of positive staining within the epidermis and dermis. Sections were independently examined by two investigators.

Only cells in which staining could be identified without doubt was considered to be positively stained; this was determined independently by two investigators. The surface area of the epidermis or dermis was measured with the help of a reticule/grid $\left(10 \times 10 \mathrm{~mm}\right.$ with $1 \mathrm{~mm}^{2}$ boxes; Microscoptics, Inc., Milford, MI) placed in the microscope's eyepiece. The number of cells positive for a specific molecule per square $\mathrm{mm}$ of epidermis or dermis was calculated by dividing the total number of positive cells by the surface area [24, 25].

\section{Statistical analyses}

For analyses of FACS data, calculations of absolute cell numbers and comparisons of means/medians of each phenotype under different experimental conditions were performed using the FlowJo software (TreeStar Inc., Ashland, OR). Statistical analyses were performed with the JMP statistical software package (SAS Institute, Cary, NC). Cell proliferation data were analyzed by ANOVA. For histological studies, ELISA data and Flow cytometry data mean levels or numbers of each outcome in the study group was compared to the control group via a two-sided t test. Nonparametric test (Mann-Whitney U-Test) was used if there was non-normality in data. A $P<0.05$ was considered statistically significant.

\section{Results}

IL-17RA expression in fibroblast like synoviocytes of patient with PsA

IL-17RA expression in FLS obtained from RA and PsA patients and from non-inflammatory conditions like OA and meniscal tear was detected and compared by FACS studies (Fig. 1). The expression of IL-17RA in these cells was further confirmed with western blot assays (Fig. 2). IL17R expression was found to be significantly higher in RA $(15.7 \% \pm 4.9)$ and PsA (4.5\% \pm 0.9$)$ FLS in comparison to OA FLS $(1.14 \pm 0.9 \%)$ and FLS obtained from nonarthritic meniscal tear patients $(0.81 \% \pm 0.36)$ at $P \leq 0.05$ (Fig. 1). Analysis of the IL-17RA protein expression in these cells was determined by western blotting assay and confirmed the flow data (Fig. 2). The relative intensities (RI) of IL-17RA expression in RA-FLS, PsA-FLS, OAFLS, and meniscal tear-FLS were 2.5, 2.4, 1.3, and 1.4, respectively.

IL-17 levels in the synovial fluid of PsA and RA are elevated

IL-17A was detected in the synovial fluid of patients with RA, PsA, and OA. The IL-17A level was highest in the PsA group $(297.5 \mathrm{pg} / \mathrm{ml} \pm 72[$ mean $\pm \mathrm{SD}])$. In the RA group, the level of IL-17A was $228 \mathrm{pg} / \mathrm{ml} \pm 58$, whereas in OA patients the level of IL-17A was $56 \mathrm{pg} / \mathrm{ml} \pm 14$. No significant correlation was observed between the synovial fluid IL-17A level and patients' treatment regiment or 
Fig. 1 IL-17 receptor A expression on FLS i 2D FACS plot showing Isotype control for IL-17RA along with live dead stain $P I$ propidium iodide. ii IL-17RA expression on FLS from PsA. iii Overlay plot of IL-17RA expression on FLS along with isotype control. iv Histogram showing frequency of IL-17RA positive cells in FLS obtained from $R A$ rheumatoid arthritis, $P S A$ psoriatic arthritis, $M T$ meniscal tear, and $O A$ osteoarthritis
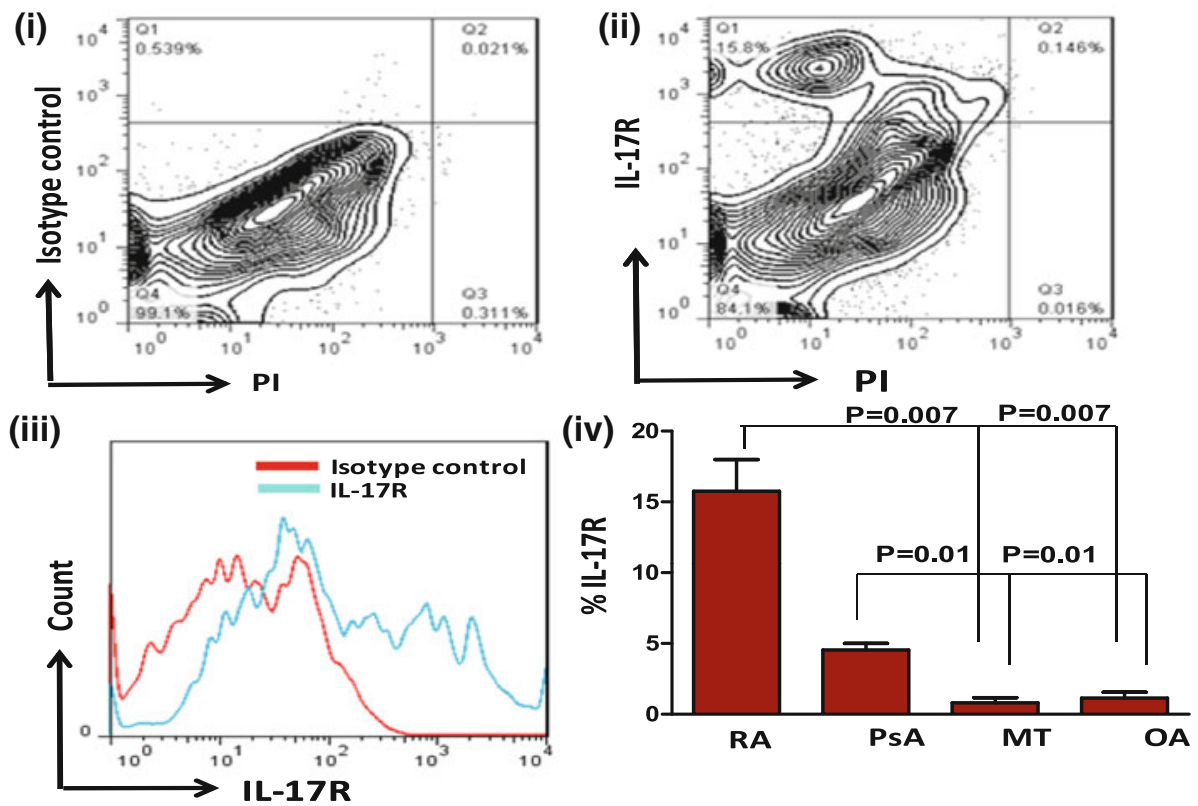

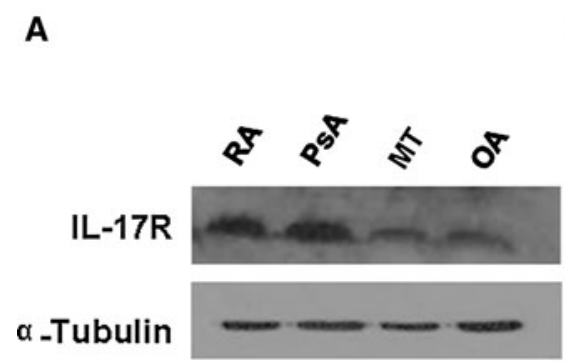

Fig. 2 Western blot analysis of IL-17RA a Expression of IL-17RA on FLS obtained from inflammatory and non inflammatory arthritis. b Histogram showing relative intensity of IL-17RA expression in FLS

disease severity. IL-17A levels of synovial fluid in PsA and RA were significantly higher compared to OA $(<0.01$, Student $t$ test). The IL-17A level in the sera of RA and PsA was $16-25 \mathrm{pg} / \mathrm{ml}$; $1 \mathrm{~L}-17 \mathrm{~A}$ was not detectable in OA and healthy control sera.

Synovial fluid of psoriatic arthritis is enriched with IL-17A producing CD4+ memory $\mathrm{T}$ cells

The high IL-17A levels in the synovial fluid of patients with PsA spurred us to explore the source of IL-17A. IL-17Aproducing $\mathrm{T}$ cells were identified in both $\mathrm{CD} 3 / \mathrm{CD} 28$ antibody and PMA/Ionomycin activated mononuclear cell populations derived from peripheral blood and synovial fluid of the study subjects (Fig. 3). Here we describe the results of CD3/CD28 antibody activated mononuclear cells because of its physiological significance. In the PBMC of PsA, RA, OA, and healthy controls and in the SFMC of OA the percentage of IL-17A+ CD4+ T cells were $<1 \%$ (Table 1). Significant

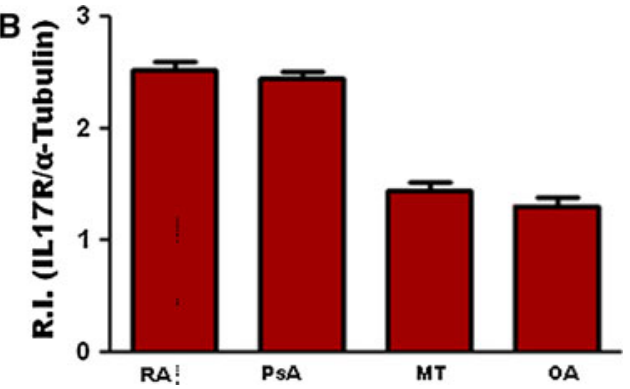

obtained from obtained from $R A$ rheumatoid arthritis, $P S A$ psoriatic arthritis, $M T$ meniscal tear, and $O A$ osteoarthritis

enrichment of IL-17A-producing T cells $(7.9 \% \pm 2.8)$ was observed within the synovial fluid as compared to the peripheral blood of the PsA patients (Fig. 3, Table 1). The majority of IL-17A+ T cells were CD4+ (Fig. 3). The frequency of $T_{h} 17$ cells were increased by tenfold in synovial fluid of PsA patients compared to OA patients $(P<.001$, Table 1$)$. The degree of enrichment did not vary with the severity of the psoriatic arthritis. Further, the majority of these CD4+ IL-17A+ were $\mathrm{CD}_{4} \mathrm{RO}^{+} \mathrm{CD} 45 \mathrm{RA}^{-} \mathrm{CD} 11 \mathrm{a}^{+}$. These results suggest that at the site of inflammation in PsA, the effector memory $\mathrm{T}$ cells are enriched with IL-17A expressing $\mathrm{T}$ cells along with upregulation of CD11a, a key molecule for the homing of T cells. Without in vitro stimulation, IL-17A positive staining for IL-17+ mononuclear cells was extremely low. There were $<0.1 \%$ IL-17A $+\mathrm{T}$ cells in unstimulated PBMC and $<0.4$ percent IL17A + T cells in unstimulated synovial fluid cells of psoriatic arthritis patients. The enrichment of CD4+ IL-17A+ T cells was observed in the SF of RA as well (Table 1). 


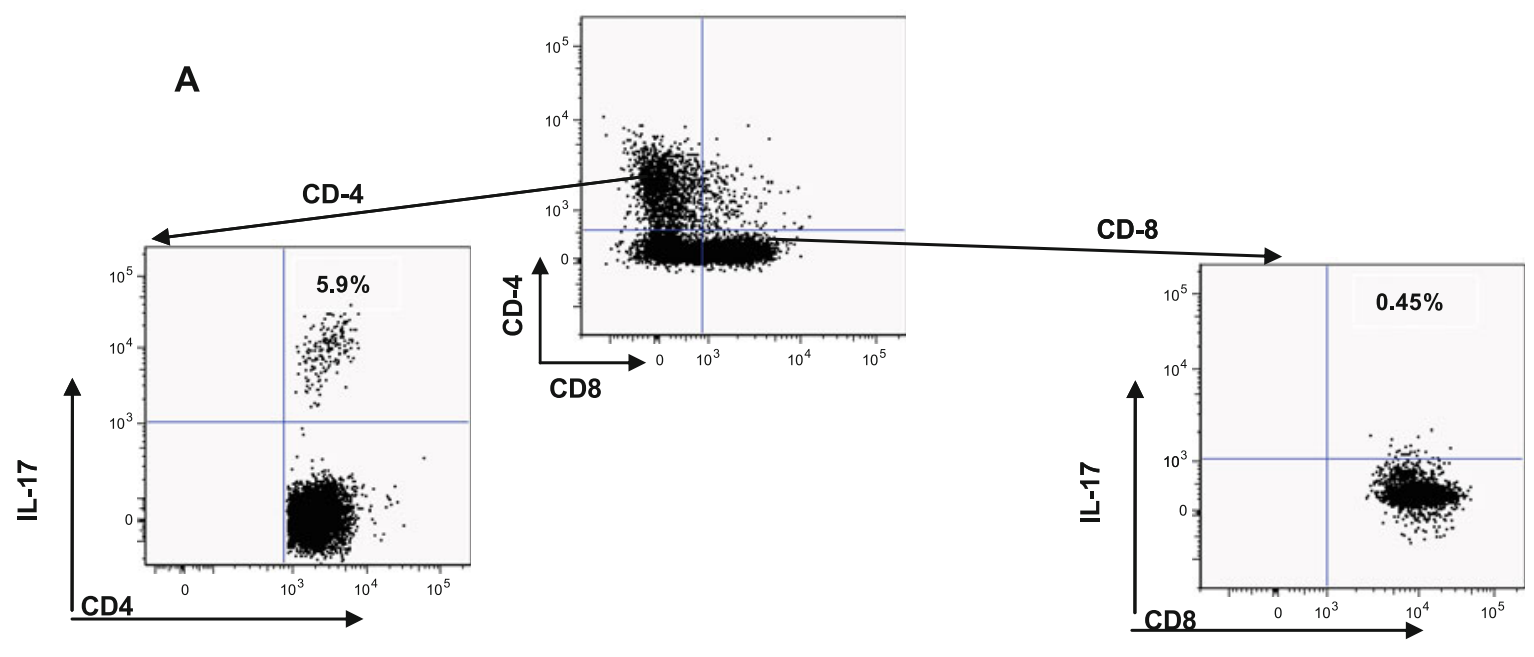

B

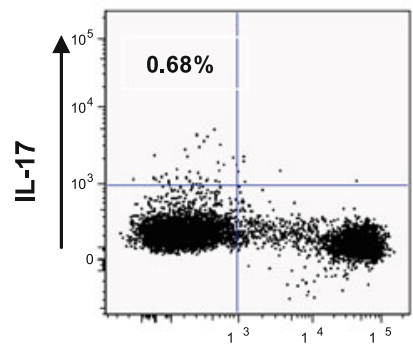

PsA derived PBMC

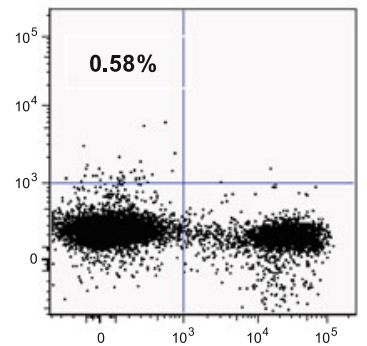

Isotype control for IL-17

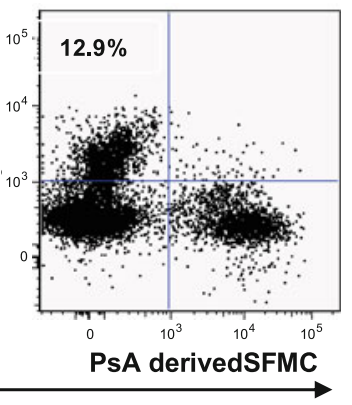

PsA derivedSFMC

\section{CD8}

Fig. 3 Synovial fluid of psoriatic arthritis is enriched with IL-17 producing T cells - representative dot plots $(n=12)$ of IL-17+ T cells. a CD3/CD28 antibody activated synovial fluid mononuclear cells from a psoriatic arthritis patient were examined for IL-17A expression by multiparameter FACS analyses. This figure shows that IL-17A expression is restricted to the CD4+ lymphocytes within the live gated CD3 $+\mathrm{T}$ cells. Compared to $0.45 \%$ IL-17A+ cells in the $\mathrm{CD} 8+\mathrm{T}$ cells there are $5.9 \% \mathrm{IL}-17 \mathrm{~A}+$ cells in the CD4+ $\mathrm{T}$ cells. b Compared to $\mathrm{CD} 3 / \mathrm{CD} 28$ antibody activation relatively more IL-

Table 1 Enrichment of CD4+ IL-17+ T lymphocytes in the synovial fluid of psoriatic arthritis patients compared to the controls

\begin{tabular}{lll}
\hline Study group & \multicolumn{2}{l}{$\%$ CD4+IL-17+ T lymphocytes (mean \pm SD) } \\
\cline { 2 - 3 } & SFMC & PBMC \\
\hline $\begin{array}{l}\text { Psoriatic arthritis } \\
(n=12)\end{array}$ & $7.9 \pm 2.8^{*}$ & $0.9 \pm 0.6$ \\
$\begin{array}{l}\text { Rheumatoid arthritis } \\
(n=8)\end{array}$ & $8.2 \pm 3.1^{*}$ & $1.0 \pm 0.6$ \\
$\begin{array}{l}\text { Osteoarthritis } \\
(n=12)\end{array}$ & $0.7 \pm 0.3$ & $0.6 \pm 0.2$ \\
$\begin{array}{l}\text { Healthy volunteers } \\
(n=12)\end{array}$ & Not done & $0.6 \pm 0.2$ \\
\hline
\end{tabular}

$* P<.001$, Student $t$ test, comparison between psoriatic arthritis and osteoarthritis; and rheumatoid arthritis and osteoarthritis. SFMC synovial fluid mononuclear cells, $P B M C$ peripheral blood mononuclear cells
$17 \mathrm{~A}+\mathrm{T}$ cells could be identified with PMA/Ionomycin activation. In gated live $\mathrm{CD} 3+\mathrm{T}$ cells derived from synovial fluid mononuclear cells (SFMC) from a psoriatic arthritis (PsA) patient it is clearly demonstrated that IL-17A+ expression is restricted to CD3+ CD8$\mathrm{T}$ cells. $\mathbf{c}$ This dot plot represents that IL-17A+ T cells reside within the memory cell pool. In gated live CD4+ T cells $>98 \%$ of the IL$17+$ cells are CD45+ (memory phenotype). PBMC peripheral blood mononuclear cells, SFMC synovial fluid mononuclear cells

Skin and synovial tissue of psoriatic disease are enriched with $\mathrm{T}_{\mathrm{h}} 17$

Serial sections from psoriatic arthritis synovial tissue (Fig. 4a, b) and psoriatic plaque (Fig. 5a, b) demonstrated that the distribution of IL-17A $+\mathrm{T}$ cells is similar to that of the CD3+ $\mathrm{T}$ cells, suggesting that IL-17A+ cells are $\mathrm{T}$ lymphocytes. Further, Fig. 5b clearly shows that IL-17A+ cells are restricted to the dermis and predominantly localized in the papillary/upper dermis. The numbers of $T_{h} 17$ cells per square millimeter of dermis were significantly higher in psoriatic dermis $(83 \pm 20)$ compared to non-lesional psoriatic skin $(7 \pm 5)(P<0.01)$. The number of $\mathrm{IL}-17 \mathrm{~A}+$ infiltrating $\mathrm{T}$ cells per square millimeter was significantly higher within the psoriatic arthritis synovial tissue $(88 \pm 22)$ compared to synovial tissues of OA 


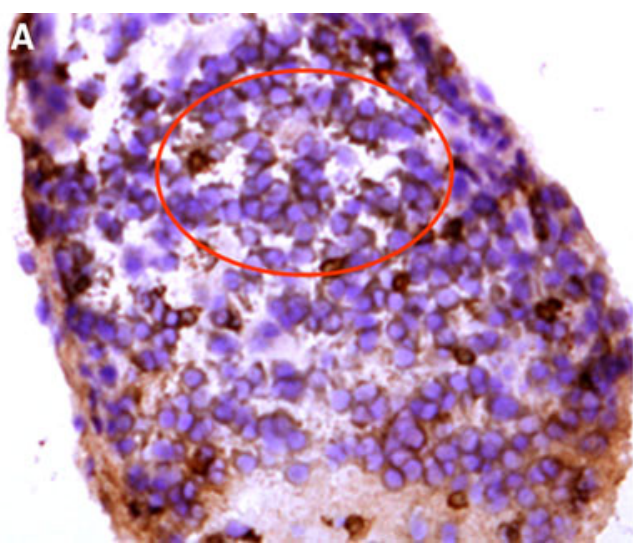

Fig. 4 Synovial tissue of psoriatic arthritis is enriched with IL$17 \mathrm{~A}+\mathrm{T}$ cells. Serial sections of synovial tissue from psoriatic arthritis stained with CD3 antibody (a) and IL-17A antibody

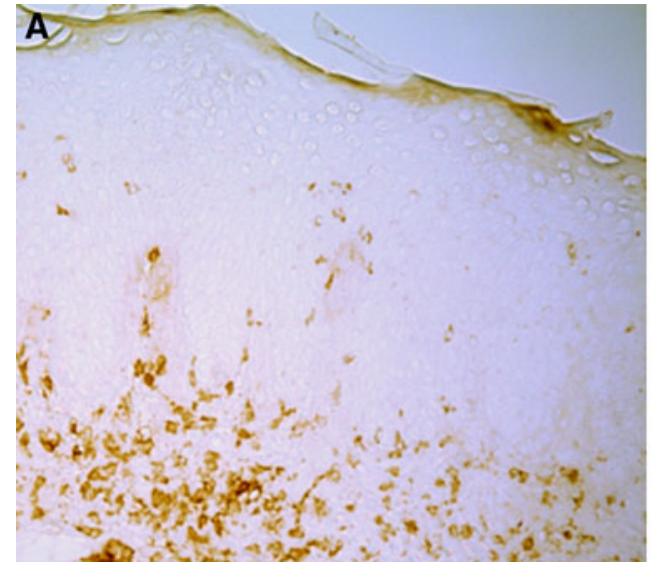

Fig. 5 Infiltrates in papillary dermis in a psoriatic plaque demonstrates IL-17A + cells. Serial sections from a psoriasis plaque stained with CD3 antibody (a) and IL-17A antibody (b). CD3+ cells (a) are

$(6 \pm 2)$ patients and patients with meniscal tears $(4 \pm 2)$ $(P<0.01)$.

In both psoriatic lesions and synovial tissue (Figs. 4, 5), the number of CD3+ cells exceeds the number of IL-17+ cells. This suggests that only a subpopulation of CD3+ cells are IL-17A producing cells; our FACS studies of lymphomononumclear cells collected from the synovial fluid of psoriatic patients substantiates this observation.

IL-17RA in FLS derived from psoriatic arthritis is functionally active: IL-17 induces marked upregulation of IL-6, IL-8, and MMP-3 in the FLS derived from PsA patients

IL-17A is a proinflammatory cytokine and has been reported to induce IL-6 and IL-8 in FLS. Here the effect of IL-17A on the expression of IL- 6 and IL-8 in FLS derived from PsA synovial tissue and compared with that of FLS derived from

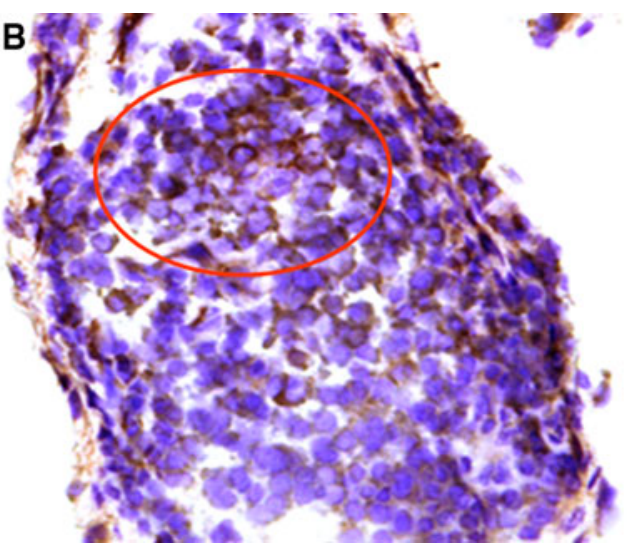

(b) demonstrating overlapping of CD3+ and IL-17A+ lymphocytes. There are more numbers of $\mathrm{CD} 3+$ lymphocytes suggesting that a subpopulation of CD3+ cells expresses IL-17A

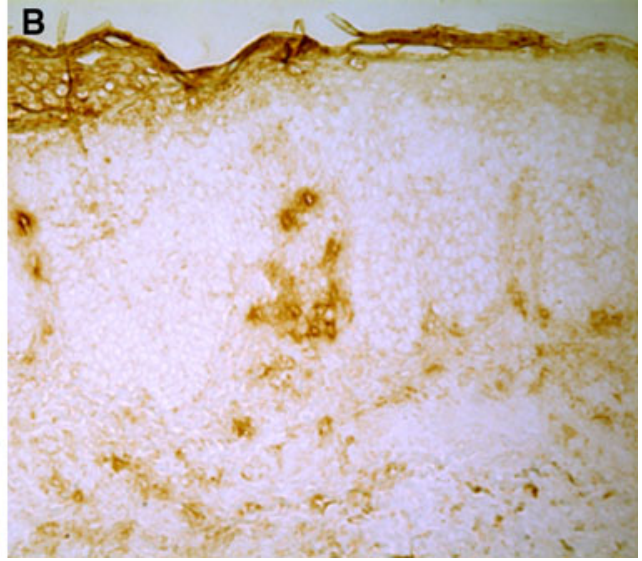

present in both epidermis and dermis whereas $T_{h} 17$ cells (b) can be seen only in upper and deeper dermis

meniscal tear patients without any underlying inflammatory arthritis. IL-17A treated FLS of PSA produced a significantly higher amount of IL- 6 and IL-8 compared to the same FLS without IL-17A treatment (Fig. 6). On the contrary, IL17A did not induce significant upregulation of IL-6 and IL-8 in the FLS of meniscal tear patients (Fig. 6). Data on the regulatory role of IL-17A of MMP-3 is sparse. Results of this study clearly demonstrate that FLS from PsA treated with IL-17A produce significantly higher amounts of MMP-3 (Fig. 6). TNF- $\alpha$ also significantly increased the production of IL-6, IL-8, and MMP-3 (Fig. 6). To further elucidate the functional significance of the IL-17RA in PsA, we investigated whether blocking the IL-17RA with a monoclonal antibody that can inhibit IL-17A, IL-17F, IL-17A/F, and IL25 cytokine signaling would impact IL-6, IL-8, and MMP-3 production. Results in Fig. 6 clearly demonstrate that an IL-17RA antibody (M202) effectively reduced secretion of IL-6, IL-8, and MMP-3. These findings substantiate that 

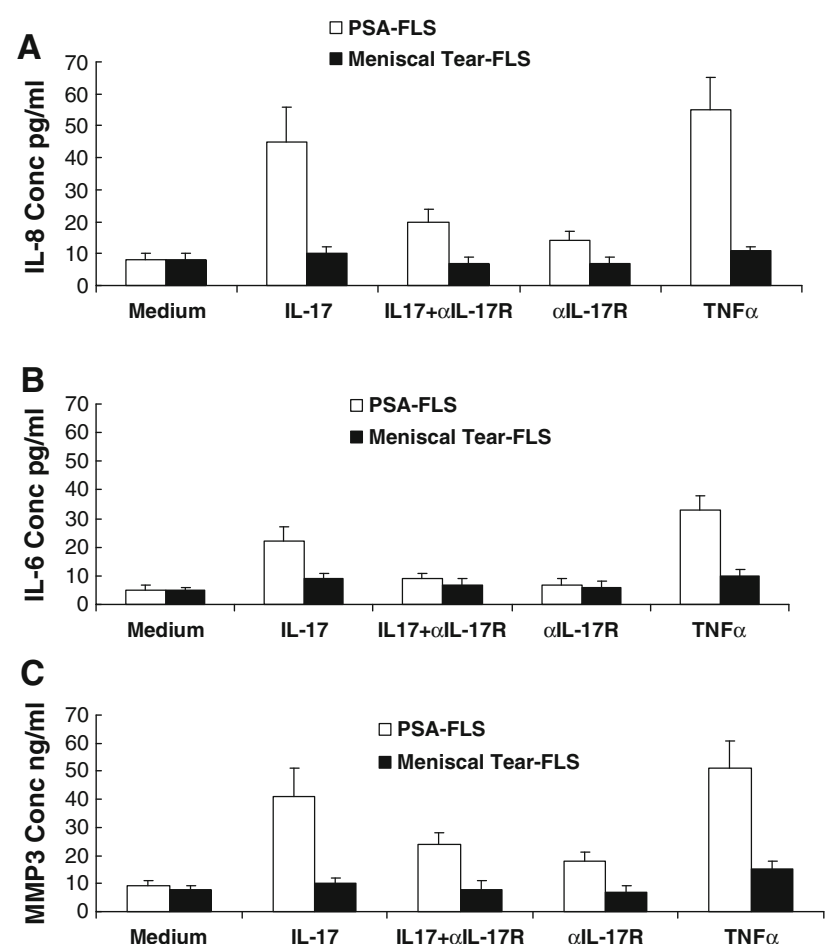

Fig. 6 Regulatory role of IL-17A and its receptor IL-17RA, on production of IL-6, IL-8, and MMP-3 by fibroblast-like synoviocytes (FLS) derived from PsA $(n=3)$ and meniscal tear individuals/normal subjects $(n=3)$. Third passage FLS $(5000$ cells/200 $\mu$ l DMEM complete medium) were cultured without/with recombinant IL-17 $(10 \mathrm{ng} / \mathrm{ml})$ or TNF- $\alpha(10 \mathrm{ng} / \mathrm{ml})$. IL-17A treated FLS of psoriatic arthritis (PsA) patients produced significantly higher amount of IL-6 (a), IL-8 (b), and MMP-3 (c) compared to the same FLS without IL$17 \mathrm{~A}$ treatment or FLS from the subjects with meniscal tear. FLS cultured with TNF- $\alpha$ served as positive controls. Induction of IL-6, IL-8, and MMP-3 by IL-17A could be significantly inhibited when FLS were culture together with IL-17A and IL-17RA antibody $(20 \mathrm{ng} / \mathrm{ml})$. This suggests that blocking of the IL-17RA with a monoclonal antibody can inhibit the IL-17A-induced production of IL-6, IL-8, and MMP-3 production

IL-17RA is functionally effective in cells from psoriatic arthritis patients.

\section{Discussion}

The regulatory role of IL-17 and its receptor system have provided a new dimension in understanding autoimmune disease processes. A series of studies have reported evidence for the role of IL-17 in various autoimmune diseases, including psoriatic disease and rheumatoid arthritis. So far, no reports are available on IL-17RA in psoriatic arthritis; functional studies of the IL-17R in other human autoimmune diseases are very limited [26-28]. Here we report the functional significance of IL-17RA in psoriatic arthritis and give a detailed analysis of IL-17-producing T cells in PsA.
IL-17RA expression was evaluated in the FLS of patients with PsA and RA and compared with IL-17RA expression in FLS of non inflammatory arthritis patients. In western blot studies, the expression level of IL-17RA in FLS of PsA patients (mean \pm SD) was significantly higher compared with FLS of OA (mean \pm SD) patients and FLS from patients with meniscectomies (mean $\pm \mathrm{SD}$ ). RI of IL-17RA in PsA-FLS, OA-FLS, and meniscal tear-FLS were $2.4,1.3$, and 1.4 , respectively. However, IL-17RA expression was found to be highest in FLS derived from RA patients (Fig. 2). Increased levels of IL-17RA expression was further confirmed by flowcytometry studies. Similar trends of IL-17R expression was observed by FACS analyses on FLS obtained from RA, PsA, OA, and meniscal tear patients (Fig. 1). In the synovial fluid of inflammatory arthritis, such as in RA and PsA, the ligand for IL-17R (IL-17) is markedly elevated. As the IL-17 receptor (IL-17RA) is expressed ubiquitously, it is expected that IL-17 and its receptor system (IL-17RA) are functionally effective in RA and PsA. So there is no teleological requirement for increased expression of IL-17R. Other studies have also reported a higher expression of IL17R in the FLS of RA compared to FLS of OA origin [27].

In this study, by various methods of investigation, an enrichment of IL-17+ T cells $\left(T_{h} 17\right)$ was observed in the skin, synovial tissue, and synovial fluid of patients with psoriasis and psoriatic arthritis. It has been proposed that IL-17 plays a critical role in the pathogenesis of psoriasis [29-32]. IL-17 mRNA has been reported in psoriatic lesions; in a murine model of skin disease, IL-17 induces autocrine IL-22 production which in turn induces psoriasiform lesions [30-32]. $\mathrm{T}_{\mathrm{h}} 17$ cells have been identified from the dermal extracts of psoriatic lesions [15]. Immunohistochemical staining of psoriasis lesions in serial sections substantiates that IL-17A $+\mathrm{T}\left(\mathrm{T}_{\mathrm{h}} 17\right)$ cells are mostly localized in the dermis (Fig. 5). In psoriasis, CD4+ T cells are known to be localized in the dermis and CD8+ T cells are mainly localized in the epidermis. The $T_{h} 17$ cells are predominantly a subpopulation of CD4+ T cells (Fig. 3), so the observed localization of $T_{h} 17$ cells in the dermis is consistent with the characteristic distribution of CD4+ T cells in psoriasis.

IL-17A levels in synovial fluid from PsA and RA patients were significantly higher compared to OA patients $(P<0.01$, Student $t$ test $)$. Other groups have also identified IL-17A in the SF of PsA patients [18, 33, 34]. To obtain a better insight about the role of IL-17A in PsA, $T_{h} 17$ cells were also studied in the synovial tissue and in mononuclear cells derived from SF (Figs. 3, 4). The IL-17A+ T cells were largely $\mathrm{CD} 4+$ and were $\mathrm{CD} 45 \mathrm{R}+\mathrm{CD} 45 \mathrm{RA}-$; this is consistent with earlier observations that IL-17A + T cells reside within the memory pool $[2,5] . \mathrm{IL}-17 \mathrm{~A}+\mathrm{T}$ cells were present at significantly higher numbers in the synovial 
fluid than in either the paired blood samples from PsA patients or the blood of OA patients and the healthy controls. By the immunohistochemistry study, we have also shown that PsA synovial tissues are enriched with IL-17A+ T cells (Fig. 4).

In a recent study, Jandus et al. [35] sorted circulating CD4+ T cells from 20 seronegative spondylarthritic patients, including ten patients with PsA, and cloned these cells in the presence of low dose IL-2. A significant proportion of the clones from these patients were shown to produce detectable amounts of IL-17 upon stimulation with CD3 and CD28 antibodies. The cloned CD4+ T cell from blood is not biologically the same as the functional $\mathrm{T}$ cell at the disease site. In that respect, results of this study are more meaningful. Here, freshly isolated effector $\mathrm{T}$ lymphocytes were studied from the synovial fluid in the diseased joints and a significant enrichment of $T_{h} 17$ cells was observed in patients with clinically active PsA. In our study population, all patients had clinically active psoriatic arthritis. However, we did not notice any correlation between disease severity and levels of IL-17 or numbers of Th17 cells in the synovial fluid. In a report by Fiocco et al., authors have noticed that following treatment with intraarticular injection of Etanercept in psoriatic arthritis, there was no significant reduction of synovial fluid IL-17 levels compared to the pretreatment levels of IL-17. Although there was a statistically significant reduction in posttreatment IL-1b, IL-1Ra, IL-6, and IL-22 levels with respect to basal values. In a recent study, Leipe et al. [34] have reported that in DMARD naïve patients, the frequencies of Th17 cells and levels of interleukin-17 correlated with systemic disease activity in PsA patients (mean disease duration $<3$ months). Our patient population and patients of Fiocco et al. were not of early onset and were not DMARD naïve. Thus, disease pattern, treatment regimen, and ethnicity of patients were different in these studies and outcomes of these results may not be comparable.

Several reports suggest that IL-17 can influence bone and cartilage destruction in inflammatory arthritis [36, 37]. In animal arthritis models, disease severity is less in IL-17deficient mice [38]. Treatment with an anti-IL-17 antibody is therapeutically effective and reduces IL-6 levels and bone erosion [10, 39]. IL-17 receptor deficiency results in impaired synovial expression of IL-1 and MMP-3, MMP-9, and MMP-13 and prevents cartilage destruction during chronic reactivated streptococcal cell wall-induced arthritis [40]. Other investigators have reported that IL-17A upregulates the expression of IL-6, IL-8, MMP-1, and MMP-3 in cultured FLS from RA and JIA [6, 41]. Recently, these observations have been substantiated with co-cultures of RA-FLS and Th17 cells; further it was noticed that IL-17A neutralization could suppress these actions of the Th17 cells [42].
To understand the role of IL-17/IL-17RA in the joint pathology of PsA, the effect of IL-17 in PsA-FLS was determined in respect to production of proinflammatory cytokines and endopeptidase. Results of this study suggest that FLS from PsA patients are tuned to a robust response following stimulation with IL-17A (Fig. 6). There was a marked upregulation of IL-6, IL-8, and MMP-3 upon exposure to IL-17A in cultured FLS from all three PsA patients (Fig. 6). These results indicate that IL-17A can enhance inflammation and cellular infiltration in the synovium; IL-17A can also mediate bone and cartilage damage in PsA. The functional significance of IL-17RA was further substantiated by demonstrating that the use of a monoclonal antibody against IL-17RA inhibits the expression of proinflammatory cytokines and metalloproteinases. Thus, IL-17RA blocking might be a potential target for developing new therapeutic approaches for psoriatic arthritis.

It is important to understand the role of $T_{h} 17$ cells in the initiation and maintenance of the psoriatic disease process. Studies have demonstrated that the p40 subunit and the IL23 specific p19 subunit, not the IL-12-specific p35 subunit, are highly expressed in monocyte and DC in psoriatic skin lesions [43-45]. Recent reports suggest that targeting the shared IL-12/IL-23 p40 subunit is an effective treatment for psoriasis [46, 47]. These observations suggest that IL23 produced by the activated DC is likely an upstream event in triggering the inflammatory and proliferative cascades of psoriasis [42-47]. IL-23 activates the $T_{h} 17$ cells to produce $\mathrm{T}_{\mathrm{h}} 17$ cytokines such as IL-17 and IL-22. $\mathrm{T}_{\mathrm{h}} 17$ cell derived cytokines will have more downstream effects such as epidermal thickening, angiogenesis, and cell trafficking [5, 7, 25-27, 47-49].

To summarize, the results of this study suggest that synovial tissue in psoriatic arthritis is enriched with IL-17 and its most well-recognized receptor, IL-17RA. It was noticed that IL-17RA is functionally active in psoriatic arthritis; it regulates the expression of cytokines and matrix metalloproteinase, which are essential for the disease process of psoriatic disease (Fig. 6). Earlier reports suggest that IL-17 also promotes bone erosion through the upregulation of RANKL [9, 39], a key regulator of osteoclastogenesis. RANKL has been demonstrated in high levels in psoriatic arthritis [50]. Thus, the downstream effects of IL-17 are likely to influence all the major components of the pathologic events of psoriatic disease in skin and joint tissues. The cellular and molecular studies described here support the hypothesis that IL-17A/IL17RA contribute to connective tissue and epithelial tissue remodeling in psoriatic disease. Further, the results of this study support that blocking of IL-17RA with a monoclonal antibody could be a therapeutic option for psoriatic arthritis. 
Acknowledgment This study was supported by a grant from East Bay Institute for Research and Education, Martinez, CA.

\section{References}

1. Harrington LE, Hatton RD, Mangan PR, Turner H, Murphy TL, Murphy KM, Weaver CT (2005) Interleukin 17-producing CD4 effector $\mathrm{T}$ cells develop via a lineage distinct from the $\mathrm{T}$ helper type 1 and 2 lineages. Nat Immunol 6:1123-1132

2. Ivanov II, McKenzie BS, Zhou L, Tadokoro CE, Lepelley A, Lafaille JJ, Cua DJ, Littman DR (2006) The orphan nuclear receptor ROR $\lambda$ t directs the differentiation program of proinflammatory IL-17-T helper cells. Cell 126:1121-1133

3. Acosta-Rodriguez EV, Napolitani G, Lanzavecchia A, Sallusto F (2007) Interleukins $1 \beta$ and 6 but not transforming growth factor- $\beta$ are essential for the differentiation of interleukin 17-producing human T helper cells. Nat Immunol 8:942-949

4. Tesmer LA, Lundy SK, Sarkar S, Fox DA (2008) Th17 cells in human disease. Immunol Rev 223:87-113

5. Hwang SY, Kim JY, Kim KW, Park MK, Moon Y, Kim WU, Kim HY (2004) IL-17 induces production of IL-6 and IL-8 in rheumatoid arthritis synovial fibroblasts via NF-kappaB- and PI3kinase/Akt-dependent pathways. Arthritis Res Ther 6:R120R128

6. Schnyder B, Schnyder-Candrian S, Pansky A, Schmitz ML, Heim M, Ryffel B, Moser R (2005) IL-17 reduces TNF-induced Rantes and VCAM-1 expression. Cytokine 31:191-202

7. Dardalhon V, Korn T, Kuchroo VK, Anderson AC (2008) Role of Th1 and Th17 cells in organ-specific autoimmunity. J Autoimmun 31:252-256

8. Ye P, Rodriguez FH, Kanaly S, Stocking KL, Schurr J, Schwarzenberger P, Oliver P, Huang W, Zhang P, Zhang J, Shellito JE, Bagby GJ, Nelson S, Charrier K, Peschon JJ, Kolls JK (2001) Requirement of interleukin 17 receptor signaling for lung CXC chemokine and granulocyte colony-stimulating factor expression, neutrophil recruitment, and host defense. J Exp Med 194:519-527

9. Kotake S, Udagawa N, Takahashi N, Matsuzaki K, Itoh K, Ishiyama S, Saito S, Inoue K, Kamatani N, Gillespie MT, Martin TJ, Suda T (1999) IL-17 in synovial fluids from patients with rheumatoid arthritis is a potent stimulator of osteoclastogenesis. J Clin Invest 103:1345-1352

10. Lubberts E, Koenders MI, Oppers-Walgreen B, van den Bersselaar L, Coenen-de Roo CJ, Joosten LA, van den Berg WB (2004) Treatment with a neutalizing anti-murine IL-17 antibody after the onset of collagen-induced arthritis reduces joint inflammation, cartilage destruction and bone erosion. Arthritis Rheum 50:650-659

11. Cua DJ, Sherlock J, Chen Y, Murphy CA, Joyce B, Seymour B, Lucian L, To W, Kwan S, Churakova T, Zurawski S, Wiekowski M, Lira SA, Gorman D, Kastelein RA, Sedgwick JD (2003) Interleukin-23 rather than interleukin-12 is the critical cytokine for autoimmune inflammation of the brain. Nature 421:744-748

12. Lan RY, Salunga TL, Tsuneyama K, Lian ZX, Yang GX, Hsu W, Moritoki Y, Ansari AA, Kemper C, Price J, Atkinson JP, Coppel RL, Gershwin ME (2009) Hepatic IL-17 responses in human and murine primary biliary cirrhosis. J Autoimmun 32:43-51

13. Nistala K, Moncrieffe $H$, Newton KR, Varsani $H$, Hunter $P$, Wedderburn LR (2008) Interleukin-17-producing $\mathrm{T}$ cells are enriched in the joints of children with arthritis, but have a reciprocal relationship to regulatory T cell numbers. Arthritis Rheum $58: 875-887$

14. Lowes MA, Kikuchi T, Fuentes-Duculan J, Cardinale I, Zaba LC, Haider AS, Bowman EP, Krueger JG (2008) Psoriasis vulgaris lesions contain discrete populations of Th1 and Th17 T cells. J Invest Dermatol 128:1207-1211

15. Scarpa R, Ayala F, Caporaso N, Olivieri I (2006) Psoriasis, psoriatic arthritis, or psoriatic disease? J Rheumatol 33:210-212

16. Teunissen MB, Koomen CW, de Waal Malefyt R, Wierenga EA, Bos JD (1998) Interleukin-17 and interferon-gamma synergize in the enhancement of proinflammatory cytokine production by human keratinocytes. J Invest Dermatol 111:645-649

17. Albanesi C, Cavani A, Girolomoni G (1999) IL-17 is produced by nickel-specific T lymphocytes and regulates ICAM-1 expression and chemokine production in human keratinocytes: synergistic or antagonist effects with IFN-gamma and TNF-alpha. J Immunol 162:494-502

18. Raychaudhuri SK, Raychaudhuri SP (2010) SCID mouse model of psoriasis: a unique tool for drug development of autoreactive T-cell and TH17 cell-mediated autoimmune diseases. Indian J Dermatol 55:157-160

19. Yao Z, Spriggs MK, Derry JM, Strockbine L, Park LS, VandenBos T, Zappone JD, Painter SL, Armitage RJ (1997) Molecular characterization of the human interleukin (IL)-17 receptor. Cytokine 9:794-800

20. Wright V, Moll JM (1971) Psoriatic arthritis. Bull Rheum Dis 21:627-632

21. Valencia X, Higgins JMG, Kiener HP, Lee DM, Podrebarac TA, Dascher CC, Watts GF, Mizoguchi E, Simmons B, Patel DD, Bhan AK, Brenner MB (2004) Cadherin-11 provides specific cellular adhesion between fibroblast-like synoviocytes. J Exp Med 200:1673-1679

22. Raychaudhuri SP, Raychaudhuri SK (2009) The regulatory role of nerve growth factor and its receptor system in fibroblast-like synovial cells. Scand J Rheumatol 38:207-215

23. Raychaudhuri SK, Raychaudhuri SP (2010) Functional significance of nerve growth factor and its receptor (TrkA) in inflammatory arthritis. Arthritis Res Ther 12:404

24. Raychaudhuri SP, Jiang W-Y, Raychaudhuri SK (2008) Revisiting the Koebner phenomenon: role of NGF and its receptor system in the pathogenesis of psoriasis. Am J Pathol 172:961-971

25. Raychaudhuri SP, Kundu-Raychaudhuri S, Tamura K, Masunaga T, Kubo K, Hanaoka K, Jiang W-Y, Herzenberg LA (2008) FR255734, a humanized, Fc-Silent, Anti-CD28 antibody, improves psoriasis in the SCID mouse-psoriasis xenograft model. J Invest Dermatol 128:1969-1976

26. Johansen C, Usher PA, Kjellerup RB, Lundsgaard D, Iversen L, Kragballe K (2009) Characterization of the interleukin-17 isoforms and receptors in lesional psoriatic skin. Br J Dermatol 160:319-324

27. Kehlen A, Thiele K, Riemann D, Langner J (2002) Expression, modulation and signalling of IL-17 receptor in fibroblast-like synoviocytes of patients with rheumatoid arthritis. Clin Exp Immunol 127:539-546

28. Honorati MC, Meliconi R, Pulsatelli L, Canè S, Frizziero L, Facchini A (2001) High in vivo expression of interleukin-17 receptor in synovial endothelial cells and chondrocytes from arthritis patients. Rheumatology (Oxford) 40:522-527

29. Nickoloff BJ (2007) Cracking the cytokine code in psoriasis. Nat Med 13:242-244

30. Li J, Li D, Tan Z (2004) The expression of interleukin-17, interferon-gamma, and macrophage inflammatory protein-3 alpha mRNA in patients with psoriasis vulgaris. J Huazhong Univ Sci Technol Med Sci 24:294-296

31. Wolk K, Witte E, Wallace E, Docke WD, Kunz S, Asadullah K, Volk HD, Sterry W, Sabat R (2006) IL-22 regulates the expression of genes responsible for antimicrobial defense, cellular differentiation, and mobility in keratinocytes: a potential role in psoriasis. Eur J Immunol 36:1309-1323 
32. Zheng Y, Danilenko DM, Valdez P, Kasman I, Eastham-Anderson J, Wu J, Ouyang W (2007) Interleukin-22, a T(H)17 cytokine, mediates IL-23-induced dermal inflammation and acanthosis. Nature 445:648-651

33. Fiocco U, Sfriso P, Oliviero F, Roux-Lombard P, Scagliori E, Cozzi L, Lunardi F, Calabrese F, Vezzù M, Dainese S, Molena B, Scanu A, Nardacchione R, Rubaltelli L, Dayer JM, Punzi L (2010) Synovial effusion and synovial fluid biomarkers in psoriatic arthritis to assess intraarticular tumor necrosis factor- $\alpha$ blockade in the knee joint. Arthritis Res Ther 12:R148

34. Leipe J, Grunke M, Dechant C, Reindl C, Kerzendorf U, SchulzeKoops H, Skapenko A (2010) Role of Th17 cells in human autoimmune arthritis. Arthritis Rheum 62:2876-2885

35. Jandus C, Bioley G, Rivals JP, Dudler J, Speiser D, Romero P (2008) Increased numbers of circulating polyfunctional Th17 memory cells in patients with seronegative spondylarthritides. Arthritis Rheum 58(8):2307-2317

36. Chabaud M, Lubberts E, Joosten L, van den Berg W, Miossec P (2001) IL-17 derived from juxta-articular bone and synovium contributes to joint degradation in rheumatoid arthritis. Arthritis Res 3:168-177

37. Koshy PJ, Henderson N, Logan C, Life PF, Cawston TE, Rowan AD (2002) IL-17 induces cartilage collagen breakdown: novel synergistic effects in combination with proinflammatory cytokines. Ann Rheum Dis 61:704-713

38. Nakae S, Nambu A, Sudo K, Iwakura Y (2003) Suppression of immune induction of collagen-induced arthritis in IL-17-deficient mice. J Immunol 171:6173-6177

39. Koenders MI, Lubberts E, Oppers-Walgreen B, van den Bersselaar L, Helsen MM, Di Padova FE, Joosten LA, van den Berg WB (2005) Blocking of interleukin-17 during reactivation of experimental arthritis prevents joint inflammation and bone erosion by decreasing RANKL and interleukin-1. Am J Pathol 167:141-149

40. Koenders MI, Kolls JK, Oppers-Walgreen B, van den Bersselaar L, Joosten LA, Schurr JR, Schwarzenberger P, van den Berg WB, Lubberts E (2005) IL-17 receptor deficiency results in impaired synovial expression of IL1 and matrix metalloproteinases 3, 9, and 13 and prevents cartilage destruction during chronic reactivated Streptococcal cell wall induced arthritis. Arthritis Rheum 52:3239-3247

41. Agarwal S, Misra R, Aggarwal A (2008) Interleukin 17 levels are increased in juvenile idiopathic arthritis synovial fluid and induce synovial fibroblasts to produce proinflammatory cytokines and matrix metalloproteinases. J Rheumatol 35:515-519
42. van Hamburg JP, Asmawidjaja PS, Davelaar N, Mus AM, Colin EM, Hazes JM, Dolhain RJ, Lubberts E (2011) Th17 cells, but not Th1 cells, from patients with early rheumatoid arthritis are potent inducers of matrix metalloproteinases and proinflammatory cytokines upon synovial fibroblast interaction, including autocrine interleukin-17A production. Arthritis Rheum 63(1):73-83

43. Chan JR, Blumenschein W, Murphy E, Diveu C, Wiekowski M, Abbondanzo S, Lucian L, Geissler R, Brodie S, Kimball AB, Gorman DM, Smith K, de Waal Malefyt R, Kastelein RA, McClanahan TK, Bowman EP (2006) IL-23 stimulates epidermal hyperplasia via TNF and IL-20R2-dependent mechanisms with implications for psoriasis pathogenesis. J Exp Med 203:2577-2587

44. Lee E, Trepicchio WL, Oestreicher JL, Pittman D, Wang F, Chamian F, Dhodapkar M, Krueger JG (2004) Increased expression of interleukin 23 p19 and p40 in lesional skin of patients with psoriasis vulgaris. J Exp Med 199:125-130

45. Piskin G, Sylva-Steenland RMR, Bos JD, Teunissen MBM (2006) In vitro and in situ expression of IL-23 by keratinocytes in healthy skin and psoriasis lesions: enhanced expression in psoriatic skin. J Immunol 176:1908-1915

46. Krueger GG, Langley RG, Leonardi C, Yeilding N, Guzzo C, Wang Y, Dooley LT, Lebwohl M, TO CN (1275) Psoriasis Study Group (2007)A human interleukin-12/23 monoclonal antibody for the treatment of psoriasis. N Engl J Med 356:580-592

47. Kimball AB, Gordon KB, Langley RG, Menter A, Chartash EK, Valdes J (2008) ABT-874 Psoriasis Study Investigators. Safety and efficacy of ABT-874, a fully human interleukin 12/23 monoclonal antibody, in the treatment of moderate to severe chronic plaque psoriasis: results of a randomized, placebo-controlled, phase 2 trial. Arch Dermatol 144:200-207

48. Toichi E, Torres G, McCormick TS, Chang T, Mascelli MA, Kauffman CL, Aria N, Gottlieb AB, Everitt DE, Frederick B, Pendley CE, Cooper KD (2006) An anti-IL-12p40 antibody down-regulates type 1 cytokines, chemokines, and IL-12/IL-23 in psoriasis. J Immunol 177:4917-4926

49. Boniface K, Bernard F-X, Garcia M, Gurney AL, Lecron J-C, Morel F (2005) IL-22 inhibits epidermal differentiation and induces proinflammatory gene expression and migration of human keratinocytes. J Immunol 174:3695-3702

50. Ritchlin CT, Haas-Smith SA, Li P, Hicks DG, Schwarz EM (2003) Mechanisms of TNF-alpha- and RANKL-mediated osteoclastogenesis and bone resorption in psoriatic arthritis. J Clin Invest 111:821-831 